\title{
LA NUEVA REGULACION DE LOS BIENES COMUNALES
}

\author{
por \\ Alejandro Nieto \\ Catedrático de Derecho Administrativo
}

SUMARIO: I. NORMAS REGULADORAS: 1. LA CONSTITUCIÓN. 2. La LEGISLACIÓN LOCAL. 3. LA LEGISLACIÓN SECTORIAL.-II. NATURALEZA JURIDICA DE LOS BIENES COMUNALES. III. LA CUESTION DE LA PROPIEDAD: 1. LOS BIENES DE DOMINIO PÚBLICO COMO OBJETO DE PROPIEDAD. 2. RELACIÓN JURÍDICA Y TITULARIDAD DE LOS BIENES COMUNALES.-IV. PRESCRIPCION.-V. RECUPERACION.-VI. EL ARTICULO 8, 4, C) DEL REGLAMENTO DE BIENES.-VII. APROVECHAMIENTO Y DISFRUTE.

El nuevo Reglamento de Bienes de las Entidades Locales ha establecido un régimen de bienes comunales, que en algunos puntos se aparta sensiblemente del anterior. Ahora bien, para comprender el alcance de estas modificaciones resulta imprescindible conectar este texto con otras normas de las que se deriva, empezando por la propia Constitución. En cualquier caso $-\mathrm{y}$ dada la limitación del tiempo de que disponemos- no pretendemos aquí examinar el régimen global de tales bienes, sino únicamente poner de relieve el alcance de las modificaciones introducidas, seleccionando a tal efecto los problemas que consideramos más interesantes. 


\section{NORMAS REGULADORAS}

\section{LA Constitución}

La nota más singular del régimen actual estriba en la circunstancia de que la materia, por primera vez en nuestra historia, ha sido constitucionalizada, lo que demuestra el interés - un tanto curioso, por no decir pintoresco- de los constituyentes por unos bienes, cuyo deterioro no sólo parece evidente sino también irreversible. La Constitución tiene una veta, que podría calificarse de romántica, que le ha inducido a aludir - ya que no a protegersectores económicos deprimidos, como es el caso, junto con los bienes comunales, de la artesanía y las zonas de alta montaña, que aparecen en el artículo 130. Sea como fuere, en el artículo 132.1 se determina que «la ley regulará el régimen jurídico de los bienes de dominio público y de los comunales, inspirándose en los principios de inalienabilidad, imprescriptibilidad e inembargabilidad, así como su desafectación".

La trascendencia de este precepto es enorme, puesto que da rango constitucional a unos caracteres de los bienes comunales que, a partir de ahora, deben ser respetados escrupulosamente por el legislador ordinario. Pero debe quedar muy claro que la regulación de dichos bienes no va a derivarse directamente del desarrollo del artículo 132.1 de la Constitución, sino que en esta misma norma se abren dos líneas legislativas diferentes ( $\mathrm{y}$ aun tres, si incluimos también al ordenamiento civil): la legislación local, por un lado, y las legislaciones sectoriales por otro. Lo cual quiere decir, por tanto, que el régimen de los bienes comunales no debe ser entendido propiamente como un desarrollo del citado artículo, sino que debe ser integrado en los ordenamientos a que acaba de hacerse referencia. En otras palabras: la Constitución respeta el sistema normativo plural aludido y lo que pretende con su artículo 132.1 es dotar de un contenido positivo al régimen de los bienes comunales, cualquiera que sea el lugar del ordenamiento en que se establezca.

\section{LA LEGISLACIÓN LOCAL}

La legislación local es, por así decirlo, la sede normativa natural de los bienes comunales, de acuerdo con nuestra tradición y con 
el carácter peculiar de sus aprovechamientos, vinculados a la condición de vecinos. Debiendo subrayar a tal propósito que el ordenamiento local posconstitucional ya se ha establecido en sus rasgos fundamentales y que en él se ha abordado minuciosamente el tema que nos ocupa, al que se dedican simétricamente los capítulos primeros de los títulos sextos tanto de la Ley de Bases reguladora del Régimen local de 3 de abril de 1985 (arts. 79-83), como del Texto Refundido de 18 de abril de 1986 (arts. 75-78) y posteriormente numerosos preceptos del Reglamento de Bienes de 13 de junio de 1986.

Esto es lo que se ha hecho hasta ahora; pero no hay que olvidar que el anuncio de las futuras leyes de régimen local de las Comunidades Autónomas puede completar este ordenamiento con disposiciones complementarias, provocando previsiblemente problemas de difícil solución, que resultan inevitables en los ordenamientos jurídicos compuestos.

El artículo 5 de la Ley de Bases ha pretendido hacer frente a esta situación, estableciendo una articulación -0 , si se quiere, jerarquización - de fuentes en la siguiente forma: "Las Entidades locales se rigen en primer término por la presente Ley y además: D) En cuanto al régimen de sus bienes: a) Por la legislación básica del Estado, que desarrolle el artículo 132 de la Constitución $b$ ) Por la legislación de las Comunidades Autónomas. c) Por las ordenanzas propias de cada Entidad».

La legislación básica del Estado encabeza así, como es lógico, la cascada normativa: $\mathrm{Y}$ aquí es donde empiezan los problemas. En primer lugar porque no sabemos si «la legislación que desarrolle el artículo 132 de la Constitución» va a ser básica, o no, como tampoco sabemos si va a ser legislación del Estado o de las Comunidades Autónomas, dado que la Constitución nada dice al respecto. $\mathrm{Y}$ en segundo lugar $-\mathrm{y}$, desde luego, esto es mucho más graveporque en la actualidad ni siquiera sabemos con exactitud si la regulación vigente del Texto Refundido es básica. La Disposición Adicional $7, b)$, no se pronuncia sobre el particular, dejando al intérprete la difícil tarea de determinarlo por su cuenta: «En las materias reguladas por el Título VI (que es el que nos afecta) se inferirá el carácter básico de sus preceptos conforme a su naturaleza o según disponga la legislación estatal vigente en aquéllas». 


\section{LA LEGISLACIÓN SECTORIAL}

Tal como se ha indicado antes, la legislación local no agota la materia de los bienes comunales, que corresponde también, y simultáneamente, a las legislaciones sectoriales. Así ha sucedido siempre entre nosotros con la legislación forestal, dada la importancia que tienen los montes comunales, y lo mismo puede suceder con la de aguas, aunque estos supuestos sean más raros y de ordinario se silencien por las normas.

La concurrencia de ordenamientos sobre una misma materia no es, por sí misma, un fenómeno reprochable; pero es claro que puede dar lugar a conflictos, cuya solución no está prevista específicamente en la Ley de Bases de Régimen local. $\mathrm{O}$ mejor dicho: en ella se determina, según hemos visto, la prevalencia de la Ley de Bases, pero es dudoso que tal solución sea válida frente a una disposición expresa en contrario, que pueda aparecer en una ley sectorial. Con el agravante, además, de que el conflicto originario de dos leyes básicas del Estado puede repercutir en otro conflicto derivado surgido en las legislaciones de desarrollo (de la local y de la sectorial estatales) de las Comunidades Autónomas. Y sin olvidar, en fin, los potenciales conflictos entre la legislación local básica y una ley estatal sectorial no básica.

El Reglamento de Bienes parece haber tomado conciencia de todos estos probemas, que intenta resolver —con legalidad cuestionable- en su artículo 1.2, donde se determina, apartándose de la Ley de Bases, que "el régimen de bienes de las Entidades locales se regirá: a) Por la legislación básica del Estado en materia de régimen local. b) Por la legislación básica del Estado reguladora del régimen jurídico de los bienes de las Administraciones públicas. c) Por la legislación que en el ámbito de sus competencias dicten las Comunidades Autónomas. d) En defecto de la legislación a que se refieren los apartados anteriores, por la legislación estatal no básica en materia de régimen local y bienes públicos. $e$ ) Por las Ordenanzas propias de cada Entidad. f) Supletoriamente por las restantes normas de los ordenamientos jurídicos, administrativo y civil». 


\section{NATURALEZA JURIDICA DE LOS BIENES COMUNALES}

De acuerdo con el régimen derogado, los bienes comunales eran bienes patrimoniales por expresa declaración legal, denunciada acertadamente como incongruente, puesto que su régimen jurídico era típicamente demanial. Situación que ha sido remediada en la actualidad, aunque haya sido en términos que distan mucho de ser explícitos.

La Constitución, según hemos visto, no se pronuncia al respecto y hasta podría entenderse que adopta la postura contraria, habida cuenta de que yuxtapone los bienes de dominio público a los comunales, como si de dos categorías diferentes se tratase.

La Ley de bases es más clara al respecto, aunque tampoco se pronuncia en términos rotundos. No obstante, la tesis demanial puede deducirse con cierta seguridad, puesto que alude a los comunales en el mismo número del artículo 79 que se dedica al dominio público. Y, sobre todo, por la dicción literal del artículo 80.1: «Los bienes comunales $y$ demás bienes de dominio público...» La interpretación demanialista se robustece, en cualquier caso y de manera definitiva, por el tenor del artículo 2.3 del Reglamento de Bienes, donde se declara ya, sin dejar espacio para la duda, que «tienen la consideración de comunales aquellos bienes que siendo de dominio público, su aprovechamiento corresponde al común de vecinos».

En su consecuencia, hay que entender derogado el régimen anterior al respecto y considerar que los bienes comunales son de dominio público, cuyo régimen genérico les es aplicable, sin perjuicio de las peculiaridades propias que les corresponden.

De la misma manera también es inequívoca la actitud de la Ley de Bases en lo que se refiere a la separación entre bienes comunales y montes vecinales en mano común, tal como se advierte en el artículo 83.

\section{LA CUESTION DE LA PROPIEDAD}

Sentado que los bienes comunales son de dominio público, surge de inmediato la grave cuestión de determinar si son objeto, o no, de propiedad. 
1. LOS BIENES DE DOMINIO PÚBLICO COMO OBJETO DE PROPIEDAD

La polémica sobre el título jurídico que relaciona a los bienes de dominio público con sus titulares es tan antigua como la propia existencia de tal dominio, habiendo dado lugar siempre y en todos los países a posiciones contrapuestas, que se han defendido con apasionamiento en uno de los torneos dogmáticos más persistentes de la cultura jurídica europea: HaURiou contra Proudhon en Francia, IHERING contra DeRnbURg en Alemania...

En España, la ambigüedad del Código Civil parece dar pie a toda clase de posiciones y suele admitirse que la "postura dominante» es la de considerar al dominio público como objeto de propiedad: así Alvarez Gendin y GarRido por influencia directa de Fernández DE Velasco, que fue quien introdujo en España la tesis de Hauriou. De la misma manera que así lo ha reconocido ocasionalmente el Tribunal Supremo (Sentencias de 27 de octubre de 1967, 17 de marzo de 1980, 28 de octubre de 1981 y 3 de diciembre de 1980), recogiendo la posición del Consejo de Estado, sentada en sus dictámenes de 14 de febrero de 1957, 10 de mayo de 1962 y 14 de junio de 1969.

Y, sin embargo, las cosas distan mucho de ser tan claras. Los propios autores civilistas, contemporáneos y primeros comentaristas del Código, negaron inicialmente la existencia de una relación de propiedad. Así MANRESA, en 1893, observando agudamente la diferencia entre "pertenencia» y "propiedad", aparentemente sutil e importada directamente del Code francés, advierte en fecha temprana que, en la letra del artículo 339 del Código Civil, «la noción de pertenecer es mucho más amplia que la de propiedad en sentido jurídico positivo que del Derecho romano se deriva" y con citas de IHERING y Ricci (el caso italiano es muy similar al español), afirma que «la relación jurídica que mantiene el Estado con estos bienes de dominio público no es una relación de propiedad sino de pertenencia, que trae como consecuencia ciertas prerrogativas jurídicas en favor del Estado como soberano territorial... Es una verdadera función de policía social y administrativa, ya de seguridad ya de servicio general. El Estado tiene bajo su acción soberana todos estos bienes; para que respondan a un fin de interés general, los cuida, los conserva y regula, cuando es preciso, el uso de los mismos». Y otro civilista, también antiguo, Víctor CoBIÁN, en 1913, sigue insistiendo con la misma rotundidad que las cosas de dominio público «no pertenecen en propiedad a nadie, ni aun al Estado, 
que sólo ejerce una protección en nombre y en interés público». Actitud que, desde otra perspectiva, se está imponiendo en la doctrina administrativista: Villar Palasí, Parejo Gámir y Rodríguez Oliver, Parejo Alfonso y Gallego Anabitarte.

La Ley del Patrimonio del Estado se mantiene en la misma ambiguiedad que el Código Civil, aunque se tiene la sensación de que ni siquiera se plantea el problema: la facilidad con que los bienes pasan del patrimonio del Estado (cuya propiedad es indudable) al dominio público, y viceversa, podría servir, desde luego, como argumento en favor de la propiedad del dominio público, si bien tal argumento diste mucho de ser contundente.

\section{RELACIÓN JURTIICA Y TITULARIDAD DE LOS BIENES COMUNALES}

Aun entendiendo resueltamente que el dominio público no está sujeto a una relación de propiedad, no por ello está decidida la cuestión en lo que se refiere a los bienes comunales, cuyas peculiaridades jurídicas son notorias.

Por lo pronto, la mejor doctrina administrativista del siglo pasado (Colmeiro, ya en 1850) venía negando la relación de propiedad: la propiedad colectiva "ocupa un lugar intermedio respecto al dominio de la Nación y al privado. La propiedad de las Corporaciones locales no es un dominio absoluto sino más bien una sustitución sucesoria en interés de las generaciones futuras. De aquí nace que se les considere en perpetua minoría y que la ley no les confiere ni la plena propiedad de sus bienes ni aun su libre administración. La tutela del estado limita sus derechos y les concede una propiedad modificada».

Mucho más tarde, en 1964 (NIETo: Bienes comunales), se ha afirmado para los bienes comunales la tesis de la «titularidad compartida" entre el Municipio, al que corresponde la administración, y los vecinos, a quienes corresponde el aprovechamiento. Tesis admitida luego sin reservas y reiteradamente por el Tribunal Supremo.

Pues bien, la moderna legislación ha dejado las cosas como están, puesto que sigue utilizando las viejas y polémicas expresiones del Código Civil, absteniéndose de utilizar la palabra propiedad en lo que a dominio público y a bienes comunales se refiere, para los que se sirve del término "pertenecer», en su artículo 79.1. Y sólo en 
el artículo 8.4.d), del Reglamento de Bienes, podría encontrarse un cierto apoyo para la tesis de la propiedad.

En definitiva, y sin necesidad de seguir ahondando en una cuestión que nos llevaría demasiado lejos, aquí se sostiene que:

a) Los bienes comunales, en cuanto que dominio público, no son objeto de una relación jurídica de propiedad en favor de los Entes locales.

b) Su titularidad es compartida, correspondiendo al Ente local las facultades de administración y conservación, y a los vecinos las facultades de aprovechamiento.

\section{PRESCRIPCION}

La imprescriptibilidad es una nota que siempre se ha predicado de los bienes comunales y que ahora ha adquirido, según sabemos, rango constitucional por imperativo del artículo 132.1 del Código Civil. A tal propósito, el artículo 80.1 de la Ley de Bases y el artículo 5 del Reglamento de Bienes reproducen el mismo texto: «Los bienes comunales y demás bienes de dominio público son inalienables, inembargables e imprescriptibles y no están sujetos a tributo alguno".

$\mathrm{Y}$, sin embargo, la cosa no ha sido nunca tan sencilla, puesto que de hecho los bienes comunales han sido objeto de una permanente usucapión en favor de los particulares, que han reducido su ingente extensión primitiva a parcelas cuantitativamente ínfimas. Ante tal realidad, sólo caben dos posiciones: o entender que se trata de una gigantes usurpación histórica, realizada a espaldas del Derecho y susceptible, por tanto, de recuperación permanente; o, por el contrario, tratar de encontrar una cobertura jurídica al fenómeno, en salvaguardia de la seguridad jurídica.

Como es sabido, esta última posición es la sostenida por García DE ENTERRÍA, quien en Dos estudios sobre la usucapión en Derecho Administrativo ha negado el mito de la imprescriptibilidad, afirmando que siempre ha sido posible la usucapión centenaria, que explica y da cobertura jurídica a una realidad innegable. Pues de entender otra cosa, habría que cuestionarse la legitimidad de casi la mitad de las propiedades inmobiliarias de España, lo que repugna al sentido común y a la seguridad jurídica. 
De este tema ya he tenido ocasión de ocuparme con prolijidad en mi citado libro sobre Bienes comunales, al que me remito. Ahora bien, como desde entonces hasta hoy han transcurrido, y no en balde, casi veinticinco años, resulta necesario revisar a fondo los viejos planteamientos, exponiendo el estado de la cuestión en 1987, a la vista de los acontecimientos que en este largo intervalo han tenido lugar.

A) Desde el punto de vista doctrinal, los autores, que inicialmente aceptaron sin reservas la brillante tesis de GARCfA DE ENTERRIA, han empezado a apartarse de ella (PAREJo GÁmIR y Rodríguez Oliver) e incluso muy recientemente Gallego ANABitarte (en El Derecho de aguas en España, 1986) ha refutado pormenorizadamente la tesis de GARcf́a DE ENTERRfa, que considera infundada con apoyo de numerosos textos legales, doctrinales y jurisprudenciales aparecidos a lo largo de nuestra historia y desde las mismas Partidas.

B) La importancia de la declaración del artículo 132.1 de la Constitución no puede obviamente ser pasada por alto, puesto que el rango constitucional del principio y la orden expresa que se da al legislador para que se inspire en el criterio de la imprescriptibilidad ha de servir también, sin duda, a las interpretaciones jurídicas, que ya no pueden prescindir de un principio constitucional.

C) En el orden normativo, la legislación vigente es, a tal propósito, rotunda. Y si bien es verdad que no eran menos contundentes los textos vigentes en el momento de la publicación de los trabajos de García DE ENTERRÍA, se han producido algunos acontecimientos enormemente significativos.

Concretamente, ha desaparecido en el actual Reglamento de Bienes de las Entidades Locales el artículo 8.5 del antiguo, que daba pie a la interpretación restrictiva de la imprescriptibilidad. Conforme a tal precepto, los bienes comunales podían, en efecto, ser usucapidos por los particulares, desde el momento en que cabía su desafectación tácita por desuso comunal durante diez años. Es decir, que, aun admitiendo la imprescriptibilidad inicial en cuanto tales bienes comunales, la usucapión era posible de forma indirecta a través del mecanismo previo de la desafectación tácita. En otras palabras: al cabo de diez años de no uso comunal (provocada por la ocupación usurpatoria del particular), el bien se convertía automáticamente en patrimonial y, una vez que esto había sucedido, se 
abrían, sin más, las puertas de la usucapión respecto de la parcela patrimonializada, con arreglo a las normas del Derecho civil.

Pues bien, al desaparecer este artículo 8.5 y al no ser posible ya la desafectación tácita, huelga decir que en ningún momento pueden empezar a correr los plazos usucupatorios en favor de los poseedores particulares, conservando con ello toda su fuerza el principio general de la imprescriptibilidad.

En la actualidad, para la usucapión por particulares sólo queda el portillo de la desafectación previa; pero ésta ha de ser expresa y formal en los términos previstos en el artículo 100.1 del Reglamento: «Si los bienes comunales, por su naturaleza o por otras causas, no han sido objeto de disfrute de esta índole durante más de diez años, aunque en alguno de ellos se haya producido acto aislado en aprovechamiento, podrán ser desprovistos del carácter de comunales en virtud de acuerdo de la Corporación respectiva. Este acuerdo requerirá información pública, voto favorable de la mayoría absoluta del número legal de miembros de la Corporación y posterior aprobación por la Comunidad Autónoma». Como se ve, ahora nos encontramos en las antípodas del régimen anterior, y no podía ser de otra manera teniendo en cuenta que la Constitución alude también directamente a la desafectación, convencida de la trascendencia práctica que tiene esta figura a efecto de la legitimación de las posibles usurpaciones.

Hoy, como ayer, los bienes comunales siguen siendo imprescriptibles sin excepciones. La diferencia estriba, no obstante, en que en el régimen anterior, la imprescriptibilidad podía soslayarse fácilmente a través del mecanismo de las desafectaciones tácitas, que en la actualidad se encuentran rigurosamente prohibidas. Las cautelas desafectadoras del artículo 100 son extraordinarias. Ya no cabe sorpresa alguna; por lo que la usucapión civil sólo puede referirse a los bienes que hayan sido objeto de patrimonialización con arreglo a las fórmulas que acaban de ser descritas y que, evidentemente, no se refieren a bienes comunales. En definitiva, tanto en el terreno normativo como en el práctico, los bienes comunales se encuentran rigurosamente protegidos contra las usurpaciones particulares. Sin olvidar, en este contexto, la eficacia recuperatoria de la potestad de esta índole que disfrutan las Entidades locales, de la que nos ocuparemos luego.

El Tribunal Supremo se ha inclinado repetidas veces por la tesis de la imprescriptibilidad absoluta de los bienes comunales, sin 
entrar a considerar el hecho de la posesión particular, que no considera relevante ni para la prescripción ordinaria ni para la extraordinaria. Así resulta de las Sentencias de 5 de enero de 1880, 27 de noviembre de 1923 y 11 de noviembre de 1986 (Ar. 6251), todas de lo civil, advirtiéndose en esta última que «los bienes comunales se hallan sometidos a un régimen jurídico que los declara inalienables, imprescriptibles e inembargables, equiparándoles a este respecto a los de dominio público». «Dado su carácter de bien del común de vecinos ha sido siempre absolutamente inalienable, además de imprescriptible, permaneciendo por tanto ininterrumpidamente en el dominio de la Entidad local».

Esta insistencia legal y jurisprudencial se explica fácilmente por la circunstancia de que los bienes comunales son cosas que están fuera del comercio de los hombres. En su consecuenca no hay forma lícita de que entren en el tráfico jurídico ni, mucho menos, en un patrimonio individual. Por cuya razón no pueden ser objeto de usucapión.

En estos términos se produce categóricamente el artículo 1.936 del Código Civil, donde se advierte que «son susceptibles de prescripción todas las cosas que están en el comercio de los hombres». Una declaración que, por lo demás, es perfectamente congruente con todo el sistema dominical del Código; y para comprobarlo basta repasar el texto de los artículos 437 («sólo pueden ser objeto de posesión las cosas y derechos que sean susceptibles de apropiación»), 447 ( «sólo la posesión que se adquiere y disfruta en concepto de dueño puede servir de título para adquirir el dominio") e incluso el 460 , en el que precisa que el poseedor puede perder su posesión por quedar la cosa fuera del comercio.

En definitiva, la imprescriptibilidad de los bienes comunales encuentra su última y más fácil justificación en el dato de que son res extracommertium, tal como ha pormenorizado la Sentencia de la Sala Cuarta de 15 de marzo de 1980: "no puede adquirir la posesión jurídica de los mismos (bienes comunales) dado el carácter que revisten de bienes extracommertium por su dedicación a un fin público que no podrían perder por un acto privado de posesión abusiva, que por sí mismo no haría desaparecer el carácter extracomercial de tales bienes".

$\mathrm{Y}$ sin que la jurisprudencia haya aceptado el dudoso portillo de la desafectación tácita del artículo 8.5 del Reglamento de Bienes de 1955, puesto que exige sin reservas un acto expreso de desafec- 
tación. Así lo advirtió ya la Sentencia de 5 de enero de 1971, reiterada en la de 15 de marzo de 1980 (Sala Cuarta): "para la desafectación de dicho destino (comunal) no basta con que el particular o particulares los hayan usurpado, sino que se precisa un acto de la Administración que así lo declare». O como dice la Sentencia (civil) de 11 de noviembre de 1986, "el alterar la calificación jurídica de los bienes de las Entidades locales precisaba expediente en el que se demostrara la conveniencia del cambio de afectación".

Más todavía: la cuestionable legalidad del citado artículo 8.5 se degrada aún más si tenemos en cuenta que primero el Estatuto Municipal de 1924 y luego la Ley Municipal de 1935 exigían para la desafectación (arts. 220.1 y 150) nada menos que un referéndum. $\mathrm{Y}$ en su base, la jurisprudencia dictada durante el tiempo de su vigencia también declaró la imprescriptibilidad absoluta de los bienes comunales mientras conservasen tal naturaleza, que no podían perder ni por desafectación tácita ni por la subsiguiente usucapión de los particulares. En la Sentencia de 10 de abril de 1933 se contempla el supuesto de una transmisión o cesión de bienes comunales acordada por el Pleno del Ayuntamiento a petición de la mayoría de los labradores (pero no referendada). Pues bien, no obstante las poderosas razones que abogaban por el mantenimiento de esta cesión -a saber, el largo tiempo transcurrido, asentamiento de la mayoría de los vecinos, conveniencia de todos, gastos realizados por el Estado, gastos realizados por el Estado y que deberían ser resarcidos en caso de devolución de los bienes, existencia de masas arbóreas repobladas por el Estado, etc.- el Tribunal anula sin contemplaciones el acuerdo de cesión, argumentando que las atribuciones de los Ayuntamientos respecto al aprovechamiento y disfrute de los bienes comunales se hallan limitadas por las disposiciones citadas, y todo acto que no se ajuste a aquellas reglas constituye una infracción legal.

En el terreno estrictamente legal, la tesis de la imprescriptibilidad no ofrece, pues, duda alguna. Otra cosa será, sin embargo, la posibilidad real de una acción reivindicatoria en tal sentido, cuando se trate de terrenos poseídos "durante mucho tiempo" por los particulares. En estos casos, la casuística de los Tribunales puede ofrecer alguna sorpresa, ya que no son inimaginables sentencias que declaren el dominio de los particulares al margen del rigor y de la claridad de las soluciones normativas y de los precedentes jurisprudenciales, que acaban de ser expuestas. 


\section{RECUPERACION}

Conexionado con lo anterior está el tema de la recuperación de los bienes usurpados. Las ocupaciones ilegítimas de los bienes comunales pueden ser remediadas siempre por los Tribunales de Justicia; pero la Ley es consciente de la eficacia y de la rapidez de la recuperación administrativa directa y, por ello, en el artículo 82 de la Ley de Bases de Régimen local se reitera una norma tradicional en nuestro Derecho: "Las Entidades locales gozan, respecto de sus bienes, de las siguientes prerrogativas: a) La de recuperar por sí mismas su posesión en cualquier momento cuando se trate de los de dominio público, y en el plazo de un año, los patrimoniales».

Precepto desarrollado en los artículos 70 y 71 del Reglamento de Bienes en términos aparentemente claros, pero que precisan de algún comentario.

El artículo 70.1 nos dice que «Las Corporaciones locales podrán recobrar por sí la tenencia de sus bienes de dominio público en cualquier tiempo»; añadiendo en el número 3 que «no se admiten interdictos contra las actuaciones de los Agentes de la autoridad en esta materia".

A) La recuperación se refiere, por tanto, a la posesión o tenencia, y así se reitera en el artículo 71.2: «La recuperación en vía administrativa requerirá acuerdo previo de la Corporación, al que se acompañarán los documentos acreditativos de la posesión, salvo que se tratare de repeler usurpaciones recientes».

La "prerrogativa» de las Entidades locales sólo se refiere, pues, al «hecho» de la posesión, que se recupera, pero no al «derecho» a la posesión ni, mucho menos, al derecho o reconocimiento de la titularidad, que sigue estando reservado a los Tribunales. Limitación que no obsta a la operatividad del mecanismo, puesto que gracias a él se consigue invertir las posiciones materiales y procesales de las partes. El ocupante (y, en su caso, usurpador) de los terrenos es desalojado por la Administración, de tal manera que ha de ser él, y no la Entidad local, quien ha de acudir al Juez solicitando la declaración y realización de su pretendido derecho. Y si lo que alega es un derecho de propiedad, habrá de demostrar previamente en el proceso que no se trata de un bien comunal (en el que la propiedad privada es imposible juridicamente), sino un bien pri- 
vado. Y si lo que alega es un título no dominical, como puede ser un derecho a la utilización privativa de un bien de la Entidad local, habrá de alegarlo ante la jurisdicción contenciosa, pero siem. pre desde fuera de la posesión, de la que ya ha sido desalojado.

Y por lo mismo, si la Entidad local no pretende únicamente asegurar y conservar su posesión, sino afirmar su derecho sobre el bien, en cuanto que forma parte de su patrimonio en calidad de bien comunal, habrá de solicitar esta declaración de los Tribunales ordinarios, dado que su prerrogativa sólo alcanza a la recuperación de la tenencia o posesión. En la práctica la recuperación de la posesión satisface de ordinario las aspiraciones de la Entidad local, puesto que a continuación ya puede esperar cómodamente a que sea el particular quien se dirija a los Tribunales con una pretensión contraria; pero quede claro que se trata de cuestiones diferentes y que si a lo que aspira es a una declaración de titularidad, a tal efecto no le basta su prerrogativa recuperatoria.

B) Este "privilegio» - sigue diciendo el número 3 del art. 71«habilita a las Corporaciones locales para que utilicen todos los medios compulsorios legalmente admitidos». Esa disposición admite, sin embargo, una grave limitación en el supuesto, nada raro, de que la ocupación se manifieste en el establecimiento del domicilio del ocupante, pues, si así sucede, quedan bloqueadas las facultades administrativas al enfrentarse con el derecho constitucional a la inviolabilidad del domicilio, según ha declarado en términos rotundos, y harto discutibles, el Tribunal Constitucional en su Sentencia de 17 de febrero de 1984. En su consecuencia, la Corporación, desprovista de su prerrogativa directa, ha de solicitar una orden judicial de entrada.

C) Cuando un terreno no sólo se encuentra poseído físicamente por un particular sino que además está inscrito en su favor (cosa muy frecuente y más cuando el poseedor tiene conciencia de la ilegalidad originaria de su posesión, pues es entonces cuando más se esmera en cumplir los requisitos formales), el supuesto es particularmente difícil para la recuperación directa, dado que el titular inscrito se encuentra amparado por los mecanismos defensivos del Registro de la Propiedad. Tal como declara solemnemente el artículo 1.3 de la Ley Hipotecaria, "los asientos del Registro... están bajo la salvaguardia de los Tribunales y producen todos sus efectos mientras no se declare su inexactitud en los términos establecidos en esta Ley». A lo que hay que añadir lo dispuesto en el 
artículo 38: «a todos los efectos legales, se presumirá que los derechos reales inscritos en el Registro existen y pertenecen a su titular en la forma determinada en el asiento respectivo. De igual forma se presumirá que quien tenga inscrito el dominio de los inmuebles o derechos reales tiene la posesión de los mismos».

Desde esta perspectiva, la afirmación municipal de que se trata de un bien comunal ve bloqueados sus efectos - la prerrogativa recuperatoria- por la presunción registral contraria, protegida, entre otros medios, por la fulminante acción procesal del artículo 41 de la Ley Hipotecaria.

Lo cual no implica, naturalmente, que el Ayuntamiento se encuentre imposibilitado de actuar, dado que la presunción registral no es, en definitiva, sino un privilegio procesal, de tal manera que lo que sucede es que el Ayuntamiento, si quiere destruir tal presunción, ha de utilizar precisamente las acciones judiciales civiles ordinarias previstas en el artículo 38 de la misma Ley: "no podrá ejercitarse ninguna acción contradictoria del dominio de inmuebles o derechos reales inscritos a nombre de persona o entidad determinada sin que, previamente o a la vez, se entable demanda de nulidad o cancelación de la inscripción correspondiente».

Importa subrayar este alcance meramente procesal de las presunciones registrales para poner de relieve que el Ayuntamiento puede destruirlas dentro de un proceso ordinario, justificando las notas de imprescriptibilidad e inalienabilidad características de los bienes comunales. Es decir, demostrada la naturaleza originaria de un bien como comunal, los actos posesorios o dominicales de un particular (incluida su inscripción en el Registro) son inválidos y no pueden prevalecer ante los derechos del Ayuntamiento, cuando éstos se ejercen en la vía procesal procedente, conforme declara el artículo 33 de la misma Ley Hipotecaria: «la inscripción no convalida los actos y contratos que sean nulos con arreglo a las leyes».

\section{EL ARTICULO 8.4.C) DEL REGLAMENTO DE BIENES}

Este artículo merece un examen detenido no tanto por la importancia de su contenido como por lo enigmático de su redacción.

El artículo 8 del Reglamento de Bienes vigente regula, como es sabido, la alteración de la calificación jurídica de los bienes de las Entidades locales, para las que exige la formación de un expediente 
(número 1), que debe ser aprobado con arreglo a unas condiciones rigurosas (número 2) y que debe traducirse, además, en una recepción formal (número 3). No obstante, y como excepción a cuanto acaba de decirse, el número 4 previene la alteración automática, es decir, sin necesidad de expediente ni de acto formal específico, en determinados supuestos y, de entre ellos letra $c$ ), cuando «la Entidad local adquiera por usucapión, con arreglo al Derecho civil, el dominio de una cosa que viniere estando destinada a un uso o servicio público o comunal».

Lo primero que llama la atención en su lectura es que dicha letra constituye un añadido a lo dispuesto en el artículo 82 de la Ley de Bases. Porque el resto del número, es decir, las letras $a$ ) y $b$ ) son reproducción literal del artículo 82 de dicha Ley. Con lo cual nos encontramos con dos sorpresas: una, la desproporción topográfica que significa el que un artículo completo de la Ley de Bases (que, al fin y al cabo, sólo dedica cinco artículos a los bienes) sólo encuentre acogida en un humilde número de un Reglamento de 135 artículos; y dos, el que el Reglamento se haya atrevido a añadir un párrafo al tenor literal de una ley, que en el resto ha transcrito con absoluta fidelidad.

Pero lo más importante, con todo, es que el precepto en cuestión resulta a primera vista ininteligible.

Para intentar llegar a su comprensión, debemos empezar preguntándonos de dónde viene. A lo que debe darse una respuesta muy sencilla. La letra que estamos analizando aparece en el artículo 4.a) del antiguo Reglamento de Bienes, aunque allí tiene un alcance literal y contextual completamente diferente. $Y$ de esta diferencia arrancan cabalmente las dificultades de su interpretación.

Para medir la distonía denunciada conviene recordar el alcance del artículo derogado: «Se entenderá, además, producida la afectación de bienes a un servicio público o comunal, sin necesidad de acto formal, cuando: a) la Entidad adquiera por usucapión, con arreglo al Derecho civil, el dominio de una cosa que viniere estando destinada a un servicio público o comunal; $b$ ) se utilizaren durante veinticinco años bienes de propios en uso o servicio público o comunal, o siendo bienes comunales, durante el mismo período de tiempo, fueren objeto de uso o servicio públicos».

Como puede comprobarse, aunque el texto de las letras es idéntico, el contexto resulta muy distinto, puesto que en el Reglamento vigente se trata de variedades de una "alteración de la calificación 
jurídica de los bienes de la Entidad», mientras que en el Reglamento derogado se trataba de una afectación a uso o servicio público o comunal. Lo que evidentemente no es lo mismo.

Por ello, el Reglamento derogado era coherente consigo mismo y de sistemática impecable, puesto que en él se regulaban tres variantes de afectación:

1. De bienes de propios a bienes de dominio público (letra $b$ ). 2. De bienes comunales (que entonces no eran de dominio público sino patrimoniales) a bienes de dominio público (letra $b$ ). Es decir, que toda la letra $b$ ) se refería a alteraciones de bienes patrimoniales, en sus dos grupos (de propios y comunales) a bienes demaniales. Y 3. Adquisición por usucapión de bienes ajenos a la Entidad local, que, por la circunstancia de venir estando destinados a un uso o servicio público o comunal, se integraban en el patrimonio municipal con la naturaleza de bienes de dominio público o comunal y no con la naturaleza de bienes de propios, no obstante que la usucapión hubiera tenido lugar con arreglo a las normas del Derecho civil.

En cambio, la variación del encabezamiento distorsiona por completo el sentido del precepto nuevo, dado que ya no puede tratarse, como antes, de una adquisición de bienes ajenos, puesto que de lo que ahora se trata es una alteración jurídica de los bienes "de las Entidades locales». Pero, mediante una usucapión es claro que ha de tratarse de bienes ajenos. Con lo cual surge la aludida contradicción entre los «bienes ajenos" implicados en el mecanismo de la prescripción, y los bienes de la Entidad local a que se refiere el encabezamiento. Con lo cual resulta que una de dos: o se trata de bienes ajenos, en cuyo caso es incorrecto el encabezamiento; o se trata de bienes que ya eran del patrimonio local, en cuyo caso no se explica la letra $c$ ), que estamos comentando.

Este precepto, en suma, ya era de difícil inteligencia, como tuve ocasión de demostrar en el citado libro de Bienes comunales; pero en la nueva redacción resulta más enigmático todavía. En definitiva, nos encontramos a lo largo de todo el número con una serie de excepciones al principio general de que la alteración de que la calificación jurídica de los bienes de las Entidades locales debe realizarse por acto expreso; pero así como las dos primeras letras son razonables, la $c$ ) parece difícil de comprender y lo único que se desprende claramente de ella es que los bienes ajenos usucapidos 
por el Municipio no lo serán en condición de patrimoniales sino de demaniales. De esta forma adquiriría sentido el precepto, aunque no pueda alabarse su corrección.

\section{APROVECHAMIENTO Y DISFRUTE}

Escasas son las modificaciones que en este punto se han introducido por la nueva legislación, desperdiciando con ello la oportunidad de «modernizar» un régimen, que parece condenado irremediablemente a la obsolescencia. Se tiene la sensación de que para el legislador constituyen los bienes comunales un resto arqueológico, que hay que respetar desde luego, pero sobre el que no vale la pena insistir, dejando su explotación a las costumbres tradicionales de los pequeños lugares en que aún subsisten. Pero también es posible que la inhibición normativa denunciada tenga otra causa más real, a saber, la preponderancia de los montes comunales y la correlativa importancia de la Administración Forestal. Así parece que la legislación local ha hecho dejación de las iniciativas modernizadoras en beneficio de la legislación sectorial de montes. Conjetura que, de ser cierta, prolongaría las tensiones que hoy existen entre los vecinos - titulares formales de los aprovechamientosy la Administración Forestal, que, a despecho de las facultades de aquéllos, es la que realmente ordena los aprovechamientos y no siempre a satisfacción de sus titulares.

La supresión que se hace en el Reglamento de Bienes a toda referencia a los cabezas de familia, es consecuencia necesaria de la previa modificación que en tal sentido había realizado ya la legislación básica del Estado.

Llama la atención, en cambio, el papel que se atribuye en esta materia a las Comunidades Autónomas, que intervienen de forma decisiva en los siguientes aspectos: a) Aprobación de las Ordenanzas locales de aprovechamientos (art. 95), incluso con audiencia preceptiva del Consejo de Estado o del órgano consultivo superior del Consejo de Gobierno de la Comunidad Autónoma, si lo hubiera. b) Y aprobación de la modalidad de adjudicación de aprovechamientos mediante precio (art. 98). 